lugic entily. During an experience of more than thirty years, I have observed only seven or eight cases, altho others may have been overlooked by me in the hasty routine of practice. The cardinal symptoms as stated are (1) lowered visual acuity for near when the distant vision is good, and (2) the presence of an iridescent vitreous reflex as revealed by oblique illumination. Nitho it recurs as a sequel of an operation for seconclary capsular cataract, its presence demands a pro forma repetition of the $V$-shaped incision in order to divide the film and restore normal vision. A cursory grlance at the literature reveals nothing of importance concerning this condition, and I have concluded, therefore, that the sulject might stimulate thoughitful discussion and the reporting of similar alses.

\title{
COMPLICATIONS IN THE INTRACAPSULAR EXTRACTION OF
}

\section{CATARACT.}

\author{
Jostelit li. Strernare, \\ BOSTON.
}

\begin{abstract}
From a personal experience with this method of operation this serics of observations is drawn. It takes up the different steps of the procedure one hy one and gives its allthors' conclusions.
\end{abstract}

Within recent years, much has been published in ophthalmic journals, relative to the advantages of removing cataract in its capsule. Papers have been read and discussed, but in very few of them have I been able to find reports dealing with postoperative developments, and the lessons learned therefrom.

My personal experience with twentythree cases of intracapsular extraction, finds me most enthusiastic over the Smith cataract operation. I have been a close follower of Dr. Fisher's suggeslions and technic, with most gratifying visual end results, in spite of the long delays of some of my cases healing, the cause of which I will touch on later. The twenty-three cases from which these deductions are drawn were ideal ones, careful examinations being made ats to histories, light projection, blood pressure, tension, tecth, urinalysis, and physical condition, ages varied from 58 to) 82 .

Tine Incision, as suggested by Col. Smith and recommended by most oth. ers, should end within the limbus, from $1 \mathrm{t}) 2 \mathrm{~mm}$. In my first nine cases this method was closely followed with wher disappointing results, requiring from 10 days to two weeks for the wound to scal tightly. This fact tempted me to try a slight conjunctival
Hilp, with pleasing results. In the next firir cases firm union was noticed at the end of the fourth day in two cases, (1) the fifth day in the third and in the remaining two, on the sixth day. Nitho contrary to the prescribed routine, eyes were inspected daily after the thirel claty, to sturly the healing progress.

Tite lemectomy. This cannot be improved upon, as now practised by most uxerators in their own manner, some cloing a preliminary, others cloing it at the time of the extraction. I believe that unless the patient is extremely restless and nervous, the iridectomy should be done at the time of the extraction, working on the supposition that entering an eyc twice increases the dinger two-fold. No preliminary iridectomies were made in my cases.

Extraction of tile Lens. To in-ure casy delivery, it is absolutely essential to make a fairly large incision. almost half of the corrieat to allow for a possible large lens. It is not only cisiential but of the atmost importance to have an assistant who thoroly understands holding the Fisher hooks. (If the cases cited, vitrcous was lost in only one (the 22nd), this being due to the faulty manipulation of the looks at the crucial moment; the case how. 
ever showed perfect healing at the end of the seventh day, and it was one where a conjunctival flap was made.

TolLet. In no case do I flush an eye after the extraction. Assuming that our field of operation is as sterile as it can be made, why introduce unecrtainties? If a little sccretion does collect I absorb it with a moist piece of cotton or withdraw it with a medicine iropper.

Many operators advise trimming the eye lashes of the eye to be operated on. I do not consider this an essential fcature, but belicve it rather detrimental. By allowing them to remain, one has something to take hold of in helping close rlown the lid after the operation and in raising it for inspection of the cye.

I have found of great value the application of yellow oxid of mercury with atropin to the lids of the operited eyc, immediately after the operation; and yellow oxid of mercury without the atropin over the lids of the unopcrated onc, my reason for this being, that some reaction will take place in the eyc-ball and that enough atropin may find its way thru the fissure to check what might be a severe iritis.

Postoperative pain occurs in most cases. This, in connection with the fact that the patients are required to lie on their backs for the first twentyfour hours, is very distressing, and calls for a sedative or a hypnotic. I have lad excellent results from the tuse of sodium bromid in doses of twenty to thirty grains, given an hour or so after the operation. It answers a twofold purpose, it is conducive to a good night's rest and relieves the nervous tension.

Since adopting the conjunctival flap, I have made it routine practice not to open the operated eye until the seventh day, al tho the dressing is changed on the third day. This being done in a darkened room without inspecting the wound. The unoperated eye is left uncovered at this time, and smoke glasses No. 4 shade provided.

Many operators claim that iritis doc's not oceur as an after complication, this claim the writer can not substantiate, as almost all my casces showed some iritic symptoms, pain, circumcorneal injection, pain which was worst luring the night and involvement of the ciliary vessels. These cases responcled readily to the use of atropin and cleared in a few days. What produces the iritis? If all has gone well the question is a most interesting one. 1 ann inclined to belicve that the hyaloid membrane is the cause of this, due to its coming in contact with the injured iris, producing a mechanical irritation.

Recently I have made use of Dr. lackson's cataract knife, the black of which is about $5 \mathrm{~mm}$. wide, rather than the one suggested by other operators and am very much pleased with it. The fact of its wilth gives a greater cutting surface with one thrust, eliminating the possible entanglement of the iris; and I suggest it be tried out. CONCLUSIONS.

The section with a slight conjunctival flap is more efficacious than the corneal onc, and healing is more rapid. This results chiefly from the blood vessels in the flap stipplying nourishment to the wound, while the cornea has to depend on its lympl supply.

Make all sections large enough to insure the delivery of a possible large lens, and no complications will result.

Of paramount importance is the proper manipulation of the Fisher hooks by an assistant who knows how.

If all has gone well, do not inspect the operated cye for a week. You will be happily surprised with the healing progress, if you have used the flap method.

A preliminary iridectomy is not essential, furthermore it may be a sourec of danger.

Iritis does oceur and calls for the use of atropin.

The use of the ointments as suggested will be found most practical.

Flushing the eye after the extraction is uncalled for, and should be dispensed with. 